Don Fitz, Cuban Health Care: The Ongoing Revolution. New York: Monthly Review Press, 2020. 303 pp. (Paper, US\$26.00)

Daniel A. Rodríguez, The Right to Live in Health: Medical Politics in Postindependence Havana. Chapel Hill: University of North Carolina Press, 202O. Xv + 267 pp. (Paper, US\$34.95)

As far as pandemic reading lists go, the inclusion of works on Cuba's health care system is strongly advised. No other country has had such a unique health care journey during the twentieth and twenty-first centuries. The nation of some 11.8 million, with a relatively humbled economy, boasts one of the most inclusive and robust health systems in the world. In addition to impressive health statistics at home, such as the lowest doctor to patient ratio anywhere in the world, Cuba's commitment to global health is also commendable, with tens of thousands of health workers serving in overseas brigades or contracts at any given time. During the pandemic, Cuba has pursued innovation in vaccine development, offered medical care to other nations, and even received COVID-19-ridden cruise ships in its ports for medical care. The country fared well through the COviD pandemic until Christmas 2020, when flights to the United States began to operate; that brought an uptick from single digit cases to hundreds a day.

The development of Cuba as a medical power in global health is complex, impressive, challenging, and always in a process of development. Two recent works that explore the subject, are Don Fitz's Cuban Health Care: The Ongoing Revolution (especially helpful for those who have almost no knowledge of the Cuban health landscape), and Daniel Rodríguez's The Right to Live in Health, an insightful, controversial, and engaging read for seasoned scholars of Cuban health care. Fitz's book provides some essential first steps in understanding how the Cuban Revolution has planned and executed health care, while Rodríguez offers an impressive contribution to a poorly understood era of Cuban medical history.

Fitz's book demonstrates how much the Cuban approach to health care differs from other places. It is universal, it is grounded in community-oriented primary care, it requires intersectoral collaboration to treat both patients and communities, it has a solid core dedicated to overseas service, it boasts impressive health outcomes at a population level, and it suffers from an interminable lack of resources. Fitz's presentation echoes a lot of what already exists in the literature, while blending it with his own excellent stories, interviews, and narratives. The idea is to give readers a personal sense of the health experience in Cuba. The key points about the origins of medical internationalism, the impor- 
tant transformations of medical solidarity in Angola, and the establishment of the Latin American School of Medicine (ELAM) as a ground breaker for foreign policy and medical capacity building are all essential cornerstones for understanding the Cuban health experience.

Fitz includes narratives and interviews with the foreign students who are following ELAM's courses (without charge) as a way to underscore ELAM's global impact. He has dedicated great effort to illuminating the unique nature of Cuban health care, and concludes the book with a chapter asking what Che Guevara would do about Covid-19.

Such reflections, while engaging readers with a sense of Cuban history, risk contributing to some misunderstandings about the nature of Cuban health policy. The suggestion is that most of Cuba's innovations originated in Cuba, when in fact a great deal of Cuba's inimitability was taken from the best international practices of community health delivery, medical education, and global outreach. The polyclinic concept had origins in the Soviet Union, and the focus on primary care first came from the USSR Semashko model. Cuba's universal health insurance system was put in place in the 196os and has obvious similarities to Britain's NHS model. This is to say that a lot of the innovations in Cuba's health system have been borrowed from international recommendations and guidelines, but it is Cuba's ability to put these guidelines into practice, where other countries fall short, that makes its system so unique. This point invites the question: if Cuba can invest so deeply in health for all, then why can't others? Which is exactly what Fitz attempts to answer.

While Fitz takes a deep dive into the experiences and narratives of Cuban health care since 1959, Rodríguez goes further back into the archives of Cuba's prerevolutionary, postrepublic, and neocolonial health care, exploring health care practices from 1902 to 1959 . This is an era that is badly understudied by scholars interested in Cuba's health system and its origins. Rodríguez provides abundant details about the way health workers and politicians organized their efforts in Havana before the 1950s. The Right to Live in Health is in many ways a missing link to better understanding the evolution and division of health care in Cuba during the twentieth century. Before 1959 the country was internationally recognized as a hemispheric leader in health research, but had almost no affordable or reliable health care services outside of Havana. Charities and state-sponsored outreach for health care services were common in Havana in the early part of the twentieth century, but rural areas were inundated with malaria, cholera, parasites, and other scourges that kept mortality for children under five alarmingly high, compared to any other country in the Americas. It is why Rodríguez's story matters, as the details, and the care with which he presents them, draw a complex picture of the relation between 
health practitioners, government officials, patients, and those excluded from care.

In a sense, the characters that Rodríguez highlights, such as Carlos Finlay, Juan Guiteras, Joaquín Jacobsen, and Jorge Le-Roy y Cassá, were all of scientific prominence for both Cuba and their era. The rich detail that he provides gives an excellent sense of the way Cuba's health system emerged. In viewing this emergence, a grain of salt, if not an entire shaker, should be taken. The story of Cuba's earliest tracings of an organized health system took place amid middleclass, educated urban men who were not of color. This is the entire frame in which students and scholars should approach Rodriguez's book. It is important to avoid the assumption that the innovations, outreach, charity or pre-1959 national health policy in Cuba were seedlings of Cuba as a medical or global health power. They were not. Prerevolution health care in Cuba was about preventing illness among a certain class and "race" of people. Innovations were taking place amid a larger, and more oppressive backdrop of inequality that influenced the interactions, land, and life of Cuba, including its politicians and leaders. Rodríguez admits this, but in highlighting some of the key characters in health or policy in 1930s and 1940s Cuba, it is erroneous to suggest that this was a truly inclusive project.

The origins of medical outreach in the Americas, especially in countries heavily influenced or controlled by the United States were largely grounded in an effort to halt the spread of disease among workers who produced key products like sugar in Cuba, or bananas in Central America. This mirrors the events of other nations wanting to improve hygiene and vaccination in order to keep the affluent from falling ill. It was not an era of equity for women's health, Afro-Cuban health, or rural health, nor was it assuring wide-spread rights to all citizens, goals that lay at the heart of postrevolutionary health care in Cuba. As Rodríguez claims, the language of Cuban health policy in the early twentieth century was inclusive for everyone, but in practice it was not delivered to all. The gravity of intentionally denying some citizens access to health is a point that readers should keep in mind while exploring the intricacies of Havana's middle-class innovations in prerevolutionary health policy.

Fitz and Rodríguez are contrasted less by their time lines (Fitz in postrevolutionary Cuba, and Rodríguez in prerevolutionary Cuba), and more by the depth of their content. Fitz has put together a great reader for newcomers to the literature on Cuban health programs, and it would serve well as a complementary undergraduate text or an enjoyable airplane read (providing that we ever get back into airplanes again). Rodríguez offers some missing links in the history of Cuban medicine that will be rich, controversial, engaging, and important to 
scholars of Cuban health care. Both books offer stories of individuals who work tirelessly to see that there is more health in a world where it is so desperately lacking.

\section{Robert Huish}

International Development Studies, Dalhousie University,

Halifax NS, Canada

huish@dal.ca 